\title{
DA CONSCIÊNCIA NACIONAL A AMÉRICA PROFUNDA: UM COTEJO ENTRE DIEGO PRÓ E RODOLFO KUSCH À LUZ DO PENSAMENTO DE E. DUSSEL LUCIANO COSTA SANTOS ${ }^{1}$
}

\begin{abstract}
RESUMO: No artigo a seguir, apresentaremos um escorço dos textos de Diego F. Pró e Rodolfo Kusch, publicados no livro-manifesto coletivo Hacia una Filosofía de la Liberación Latinoamericana, de 1973, que promoveu o lançamento mundial da Filosofia da Libertação. O cotejo desses textos terá como perspectiva norteadora o pensamento de E. Dussel - um dos mais proeminentes remanescentes da Filosofia da Libertação - e permite a apreciação de dois modos emblemáticos de considerar as questões estratégicas da nacionalidade e do povo, a partir da América Latina assumida como lugar hermenêutico e em chave de libertação decolonial.
\end{abstract}

PALAVRAS-CHAVE: Filosofia da Libertação. Nacionalidade. Povo. Decolonialidade.

ABSTRACT: In the following article, we will present a summary of the texts by Diego F. Pró and Rodolfo Kusch, published in the collective manifesto book Hacia una Filosofía de la Liberación Latinoamericana, which promoted the worldwide launch of the Philosophy of Liberation. The collation of these texts will be guided by the thought of E. Dussel - one of the most prominent remnants of the Philosophy of Liberation - and allows the appreciation of two emblematic ways of considering the strategic issues of nationality and the people from Latin America, assumed as a hermeneutic place and a key to decolonial liberation.

KEYWORDS: Philosophy of Liberation. Nationality. People. Decoloniality.

Em 1973, veio à luz o livro-manifesto Hacia una Filosofía de la Liberación Latinoamericana, composto quase inteiramente por intelectuais argentinos, que marcou o lançamento da Filosofia da Libertação como movimento coletivo de ideias no âmbito da produção filosófica mundial. No texto a seguir, apresentaremos um escorço de dois textos dessa obra - de Diego F. Pró e Rodolfo Kusch -, cujo cotejo permite uma apreciação de dois modos emblemáticos de considerar as questões estratégicas da nacionalidade e do povo, a partir da América Latina assumida como lugar hermenêutico e em chave de libertação decolonial.

\footnotetext{
${ }^{1}$ Professor Titular de Filosofia da Universidade do Estado da Bahia (UNEB), credenciado no Programa de PósGraduação em Educação e Contemporaneidade (PPGEDUC). Doutor em Filosofia pela Pontifícia Universidade Católica do Rio Grande do Sul (PUC-RS). E-mail: lucostasantos1@gmail.com.
} 
Apresentado como subsídio no Seminário "Filosofia de la Liberación: Perspectivas y Prospectivas" (2019) da Associación de Filosofia de la Liberación (AFYL), dedicada a estudar o pensamento de Enrique Dussel, o texto parte deste como referência hermenêutica de fundo para a abordagem dos autores em tela, o que se mostra tanto mais oportuno tendo em vista a contribuição paradigmática de Dussel na estruturação de algumas das linhas mestras da Filosofia da Libertação.

A fim de melhor ressaltar a singularidade da visão dos autores mencionados, e como se articulam (e contrastam) no âmbito programático da Filosofia da Libertação, assumimos como estratégia hermenêutica perguntar que sentido forte de libertação subjaz aos textos aqui comentados, ou, mais propriamente, do quê e para quê se trata de libertar-se.

\section{Diego F. Pró (1915-2000): “Americanismo e europeísmo em Alberdi e Groussac"}

O texto de Diego F. Pró, professor de Lógica e História do Pensamento Argentino na Universidade Nacional de Cuyo, propõe uma perspectiva de leitura em contraste com a matriz analética dusseliana, inspirada na categoria levinasiana de alteridade e de influência fundante na construção da Filosofia da Libertação. Pró inspira-se no "movimento em favor do comum destino americano" (PRÓ: 1973, 188), próprio das lutas anticoloniais dos sessenta e, com base nisto, propõe que se pense e afirme o sentido da "cultura americana", o sentido da cultura de Nossa América. Seu texto é um libelo em prol da afirmação e emancipação das nações "nuestroamericanas". Reivindica a assunção do que nos é próprio e que se encontra historicamente ignorado ou suprimido. Em sua perspectiva, chamam a atenção três significativas decisões discursivas: primeiro, a opção estratégica preferencial pela categoria de "nação", ao invés de "povo"; em seguida, a aposta na cultura como principal fator de emancipação nacional; por fim, o uso do termo "emancipação" no mesmo sentido de "libertação", pois, neste momento, a importante distinção entre esses termos não parecida ainda suficientemente estabelecida. ${ }^{2}$

Segundo Pró, a busca de um comum destino americano tem como condição de possibilidade a conquista de uma “cultura americana com características próprias”. (PRÓ: 1973, 187)

Sem desconsiderar a importância de aspectos como geografia, raça e formas de governo, para o autor tais fatores não constituem, por si mesmos, a "raiz" da "maneira de ser" de uma nação, se desvinculados de sua "consistência cultural", conferida pela "vontade de viver juntos,

\footnotetext{
${ }^{2}$ Para a distinção entre os conceitos de emancipação e libertação, cf. DUSSEL, E. 14 Tesis de Ética. Hacia la Esencia del Pensamiento Crítico. Madrid: Editorial Trotta, 2016, 197 e ss.
} 
com os mesmos ideais, tradição e valores." (PRÓ: 1973, 188). Ou seja, uma nação se constitui como tal por sua cultura - pelo modo como projeta a si mesma a partir de suas tradições e valores - e esta é uma obra de construção histórica, em interação dialética com os demais elementos condicionantes da formação nacional.

No debate sobre se existe ou não uma cultura americana original, Pró assinala três posições: 1) Os que a negam; 2) Os que a afirmam; e 3) Os que afirmam haver um começo de cultura original - ficando claro, no andamento do texto, que o autor se inclina para a terceira posição. Mas, em que consiste propriamente tal originalidade? Sobre esta questão, Pró distancia-se dos que creem ser possível edifica-la a partir da unidade política-linguística dos povos hispanos. Com efeito, ainda que o projeto político da unidade hispano-americana configure um "belo ideal", a seu ver ele não poderia plasmar a americanidade sem referência orgânica aos demais aspectos (econômicos, geográficos, sociais etc.) dos respectivos países, com suas singularidades específicas.

Em definitivo, a questão da cultura americana pressupõe "una maneira de ser netamente americana, acompañada de la conciencia y autoconsciencia de la misma”, em seus mais diversos aspectos e com seus respectivos sistemas de valores, de modo que se possa "coadyuvar a su desarrolho mediante el conocimiento de su naturaleza y tendências." Em suma, "La más alta conquista de esa cultura será la autoconciencia de sí misma para conocerse em su autodesarollo." (PRÓ: 1973, 190). Sem tal trabalho orgânico de introspecção histórica sobre o magma vital da própria nação, a cultura ficará restrita a seus "núcleos dirigentes", sendo esterilmente entendida como "ornamento que da brillo exterior a la vida de sus pueblos." (PRÓ: $1973,190)$

Segundo Pró, nem mesmo a presença ostensiva da cultura europeia impede a constituição da americanidade pela via da autoconsciência cultural, uma vez que a herança importada já está assimilada à vida de nossos povos e pode servir de canal para a expressão de seu sistema de valores. A questão não é falar em castelhano - ou manejar as artes, técnicas, ciências e filosofia -, mas fazê-lo com "voz própria". Assim, não se trata de prescindir da cultura europeia, mas de apropriar-se desta a partir de uma cultura "americanizada" e "americanizante".

Antes de seguir com o texto, convém indagar até que ponto é lícito - ou, ao menos, o quanto é arriscado - se falar em "maneira de ser claramente americana", com tal acento substancialista, ou em "americanidade" e "voz própria" - no singular -, sem levar em conta as contradições, contrastes e complexidades que fraturam e matizam Nossas Américas. 
A fim de respaldar a sua busca da cultura americana original, Diego Pró acerca-se da obra de dois importantes pensadores argentinos do século XIX.

O primeiro é Juan Bautista Alberdi (1810-1884), verdadeiro “pai da Pátria” argentina, que, junto a outros expoentes de sua geração, contribuiu de modo decisivo para consolidar a Independência de 1810 e dar-lhe a devida fundamentação filosófica, além de ser o principal artífice da Constituição de 1853. Em Alberdi, um papel histórico de tal envergadura se fez acompanhar de esforço reflexivo de igual nível, no sentido de ajudar a estabelecer as bases teóricas da Política, do Direito e da Filosofia americanos e argentinos, na linha daquela rigorosa “autoconsciência nacional” reivindicada por Diego Pró em seu texto.

A questão do sentido americano e nacional desponta com força em escritos da juventude de Alberdi. Um destes é o emblemático discurso de inauguração do Salão Literário de Marcos Sastre, em 1937, ano que justamente se erigiu em marco da assim chamada "Geração de 1937", responsável por sepultar a herança monárquica e estabelecer as bases do Estado democrático de direito - liberal - na Argentina.

Baseado no historicismo romântico alemão (de Herder e outros), segundo Alberdi há uma lei de desenvolvimento da humanidade, com seu respectivo sentido teleológico, que, realizando-se nas condições de tempo e espaço, assume a forma de leis particulares de desenvolvimento dos povos. Caberia, portanto, à sua geração, na era que se inicia após a Independência, descobrir como essas leis civilizatórias universais - tais como já se haviam institucionalizado na Europa - deveriam ser implementadas no contexto de América e Argentina.

Assim, como a história americana é um momento da história universal - leia-se ocidental-europeia -, a construção da civilização americana e argentina requer uma direção simultaneamente europeia e nacional. Aqui, tem muita importância a ideia de "plasticidade social", pois cabe às necessidades históricas americanas acomodar e "filtrar" os princípios europeus, o que em certa medida evoca os binômios matéria/forma e corpo/espírito, com os quais Sarmiento - outro expoente da "Geração de 1837" - caracteriza a relação entre a América "bárbara" e a Europa/América do Norte "civilizadas". 3

Traduzido no campo filosófico, isto significa que a filosofia é ciência da razão universal - ou seja, da razão histórica -, diversificada segundo as condições de espaço e tempo. Não deve,

\footnotetext{
${ }^{3}$ Sobre a dicotomia civilização/barbárie em Sarmiento, e sua crítica, cf. Dussel, E., Oito Ensaios sobre Cultura Latino-americana e Libertação. São Paulo: Paulinas, 1997.
} 
portanto, encerrar-se em meras especulações, mas repercutir histórica e socialmente a vida dos povos.

Considerada desse modo, a filosofia nacional é a "autoconsciência da nação", e, como tal, só a ela cabe orientar o desenvolvimento "objetivo" das nações. Sem negar-se seu caráter metódico e epistemático, em América a filosofia só se justifica como reflexão sobre questões derivadas da vida dos povos. É reflexão "concreta", "sintética" e "positiva", operando nos campos práticos da política, história, direito, literatura etc. Essa filosofia americana não condiz com modelos e esquemas externos, e somente é exequível por americanos, ademais envolvidos com as exigências históricas e sociais de seus povos. Em suma, em América a filosofia "debe ser política y social en su objeto, ardiente y profética en sus motivos, realista en sus procederes, republicana en su espírito y destinos." (PRÓ: 1973, 201). A partir dessa orientação, segundo Alberdi, a filosofia americana terá que pautar-se por três características fundamentais, devendo ser: 1) Expressão das necessidades mais vitais e altas dos países americanos; 2) Antirrevolucionária, pois visa superar a crise em que América seguia involucrada; 3 ) Orgânica, cabendo-lhe investigar as condições históricas da ordem vindoura.

O segundo pensador referenciado por Diego Pró é Paul-François Groussac, imigrante francês naturalizado argentino e participante da Geração de 1880, formada por aristocratas da província e da capital que deram sustentação à República Conservadora argentina.

Groussac identifica como um dos principais problemas americanos o fato de nossos povos serem meros "consumidores de civilização", quando se trataria de, segundo ele, "vivir, en parte al menos, la propia sustancia e irradiar luz original, siquiera sea débil y trémula". (PRÓ: 1973, 202). Para Groussac, a condução da história é reservada a uma minoria ilustrada, com capacidade moral e política para formar a multidão passiva. A partir dessa visão elitista de história e povo, o escritor franco-argentino atribui a pouca densidade civilizatória dos povos americanos à incompetência de seus condutores, por abdicarem de suas responsabilidades morais, científicas e técnicas, dando lugar a uma imitação acrítica do pensamento europeu.

Reflexo dessa visão elitista é a concepção de história como luta entre forças dominantes e dominadas, sendo que aquelas representam inovação, liberdade e progresso, e estas, tradição, necessidade e atraso. Por suposto, para Groussac o sentido geral da história - e aqui se nota um claro eco do romantismo teleológico de Alberdi - é a imposição das forças dominadoras sobre as dominadas. No caso da história argentina, nosso autor identifica as forças dominantes/progressistas com a Conquista, a Independência e, já em seu tempo, com o Partido dos unitários - aristocráticos, urbanos, europeístas -; ao passo que as forças dominadas estariam 
representadas, na Colônia, pelo elemento indígena e vernáculo, em seguida pelos monarquistas anti-modernos e, em seu tempo, pelo Partido dos federais - campesinos, "instintivos" e americanos. Também aqui, impõe-se o clássico binômio civilização/barbárie de Sarmiento, que abriu caminho à "portenhização" da Argentina, voltada à Europa e de costas para as camadas profundas de seu povo.

Embora Diego Pró tenha convocado os pensamentos de Alberdi e Groussac como subsídios para sua proposição do ideal de "autoconsciência nacional”, verifica-se, ao cabo, que as ideias-chave desses autores argentinos do século XIX - mais ainda, no caso de Groussac servem mais de contraste do que de fundamentação à proposta de Pró. Sobretudo, se esta for compreendida à luz do paradigma da libertação no qual pretende enquadrar-se. Ainda presos a uma filosofia de matriz liberal, esses autores não conseguem saltar para fora de uma compreensão substancialista e homogeneizadora de nação, desconsiderando a profunda fratura que cinde as sociedades americanas e ignorando o povo - enquanto alteridade oprimida e excluída da totalidade colonial - como protagonista de sua própria libertação e principal promotor de civilização nos países colonizados. ${ }^{4}$

Caso, porém, se conceda ao texto de Diego Pró um alinhamento (mesmo mitigado) à perspectiva da libertação, talvez possamos dizer que se trata aqui de uma libertação $d a$ alienação cultural para a autoconsciência nacional.

\section{Rodolfo Kusch (1922-1979): "Uma lógica da negação para compreender a América"}

No conjunto do livro-manifesto, o nome de Rodolfo Kusch, professor de Filosofia da Universidade de Buenos Aires, merece especial destaque. Em relação aos demais coautores, o pensamento e a obra de Kusch alcançaram um nível de contribuição e elaboração acima da média, chegando a imprimir uma marca inconfundível no corpus da filosofia latino-americana contemporânea. Quanto ao cotejo específico com a perspectiva ontológica aberta por Diego Pró, o texto de Kusch agrega um inusitado nível de profundidade, saindo da mera afirmação da autoconsciência nacional para uma veemente introspecção em busca das raízes históricoculturais do povo americano, notadamente em suas camadas pré-colombianas.

Tal perspectiva se traduz no título emblemático da obra mais importante de Kusch América Profunda (1961). Cabe assinalar que essa prospecção da "profundidade" de América, em Kusch, deve ser lida em chaves distintas e complementares: histórica - como recuperação da memória das origens, esquecidas em um passado supostamente "primitivo" e "ultrapassado";

\footnotetext{
${ }^{4}$ Para uma compreensão do sentido de povo em perspectiva de libertação, cf. DUSSEL, E., "Cinco tesis sobre el "populismo"”, in Filosofías del Sur. Descolonización y Transmodernidad. CDMX: Ediciones Akal, 2015.
} 
sociológica-antropológica - como afirmação da cultura dos grupos populares, oprimidos e excluídos da ordem social; psicológica - como vazão das pulsões anímicas pré-conscientes e instintivas, recalcadas pelo padrão de "homem civilizado". "Profundo", portanto, é, a um só tempo, o que se encontra muito antes (no tempo), abaixo (na sociedade) e dentro (na psique); ou seja, é, simultaneamente, o ancestral, popular e inconsciente.

Rodolfo Kusch consagra sua vida a esse árduo e fecundo trabalho de prospecção da América profunda, obrigando-se a um amplo deslocamento existencial que o impele, seja às margens da sociedade e ao interior de América, a fim de estreitar convivência com a gente do povo e deixar-se cativar pela "sedução da barbárie" gnose para dentro de si mesmo, a fim de liberar as camadas psíquicas reprimidas pela ordem "civilizada". A travessia existencial de Kusch tem o seu momento culminante após o golpe militar de 1976, na Argentina, quando, perseguido pela repressão, exila-se não para fora, mas para dentro de seu país, recolhendo-se com a família numa casinha na cidade de Maimará, na quebrada de Humahuaca, estado de Jujuy. Protegido pela paisagem do altiplano e pelo anonimato, Kusch encontra aí o melhor cenário para radicalizar sua imersão no magma popular da América e consolidar seu pensamento.

Semelhante deslocamento existencial - para além do próprio lugar, classe social e centro psíquico - só se sustenta a partir de uma "fé" no povo americano, tal como Kusch o menciona de passagem no início de seu texto. Isto lembra a "fé existencial" na palavra (dabar) do Outro, que Dussel descreve como princípio do método analético. ${ }^{6}$ Porém, enquanto em Dussel a fé existencial é consentimento à palavra do Outro - princípio de relação ética -, em Kusch ela é filiação ao povo do qual recebemos nossa raiz e destino - princípio de realização ontológica. Em Kusch, portanto, a fé no "povo americano" nos vincula, indistintamente, à comunidade ancestral, à gente "bárbara" e à dimensão anímica mais profunda de nós mesmos.

Essa imersão na cultura "bárbara" de América impregna de densa carga simbólica e afetiva o pensamento de Kusch, em cujo estilo "literário" se pode desavisadamente acusar falta de rigor. Trata-se, porém, de um outro rigor, que visa sintonizar o pensamento com a complexidade da consciência popular, sem que lhe falte a devida estruturação categorial e o diálogo com referências canônicas do pensamento ocidental.

\footnotetext{
${ }^{5}$ Título da primeira obra de Kusch, de 1953. In KUSCH, R. Córdoba: Obras Completas - Tomo I. Editorial Ross, 2000.

${ }^{6}$ Cf. DUSSEL, E., Para una Ética de la Liberación Latinoamericana - Tomo II, CDMX: Siglo XXI Editores, 2017, p. 52 e ss.
} 
À diferença de Pró, Kusch faz menção explícita à perspectiva (de)colonial, ao atribuir a uma "mentalidade colonizada" a "cegueira" que nos impede ver "o que passa com América", submetendo-nos a uma pauta cultural burguesa empenhada em reformar nosso modo de ser, pensar e viver (KUSCH: 1973, 178). Bem considerada, nossa "cegueira" colonial constitui não propriamente uma falta de visão, mas um modo inapropriado de olhar para Nossa América, a partir de um pensamento cativo da mentalidade ocidental moderna, ao qual Kusch caracteriza como "lógica da afirmação".

A lógica da afirmação ocidental moderna opera no campo proposicional, a partir da coincidência da verdade com as leis a priori do pensamento: consiste em fazer proposições assertivas, "residualizando" ou descartando o que é negado. Tal lógica atende à exigência da ciência, na medida em que esta se constrói a partir de afirmações apodíticas sobre coisas ou objetos, postos à disposição do homem moderno para sua apropriação e manipulação. Noutras palavras, se não é possível delimitar o que é o objeto e fazer asserções claras sobre ele, tampouco será possível possuí-lo e manejá-lo. Assim, a lógica da afirmação - cega para enxergar América - melhor se aclara à luz da categoria de "pátio de objetos" ", que Kusch extrai de Hartmann, segundo a qual a cidade moderna, surgida com a revolução técnica, constitui-se como espaço vazio - ou "pátio" - em que instalamos uma profusão de coisas a serviço de nossa comodidade. Em resumo: a lógica da afirmação é o modo de pensar próprio da ciência, que serve à fundação da cidade moderna como "pátio de objetos" à disposição do homem burguês.

Em contraste com a perspectiva acima, Kusch propõe uma "lógica da negação" como modo de pensar apropriado para compreender a cultura "bárbara" de América. Ao passo que a "lógica da afirmação" se limita ao campo proposicional e visa instrumentar a explicação dos objetos para operar (no sentido da téchne) sobre eles; a "lógica da negação" atua em nível ontológico-existencial, e visa propiciar a compreensão dos sujeitos para agir (no sentido da práxis) com e para eles. É uma lógica do viver a serviço do bem (con)viver.

A "lógica da negação" parte do existente em seu processo de auto-realização, em vista da totalidade de ser aberta por seu mundo. A referência ao poder-ser heideggeriano é, aqui, evidente. Nessa perspectiva, existir consiste em assumir projetos para realizar a "totalidade de ser" a que se aspira a partir do próprio mundo (KUSCH: 1973, 179). Viver é, pois, requerer a plenitude de ser pela mediação do projeto, não importando se este se realiza ou não. A julgar pelo texto aqui em exame, ao menos de três modos a "lógica da negação" incide na verdade existencial-ontológica: 1) Remetendo o sentido de cada objeto à totalidade de ser de seu

\footnotetext{
${ }^{7}$ Cf. KUSCH, R., América Profunda. Obras Completas - Tomo II. Córdoba: Editorial Ross, 2000, op. cit.
} 
transfundo cultural, a qual é indeterminada e não reconhecida de imediato ${ }^{8}$; 2) Levando em consideração as circunstâncias negativas da vida (caos, doença, morte) que se opõem à realização do projeto de ser; e 3) Positivando elementos culturais (rituais, crenças, deuses etc.) negados como irracionais pela lógica ocidental.

Note-se que a negatividade aqui em jogo não atua para além da totalidade. Pelo contrário, constitui a própria dinâmica de totalização da totalidade cultural, para além do poderser de cada existente. Não é negatividade ética-analética, mas ontológico-dialética. Assim, o campo de lucidez no qual se move o pensamento de Kusch não é a filosofia da alteridade de matriz semita, mas uma "filosofia do enraizamento" filiada ao que, mais adiante, o pensador jesuíta Juan Carlos Scannone denominará "a verdade do paganismo".9

Segundo Kusch, a razão de ser de uma cultura é dar ao existente o horizonte simbólico que possibilite a realização de seu projeto. Nesse sentido, a cultura "regulamenta a totalização", e é "correta" em qualquer caso, ainda quando se trate, por exemplo, de um projeto religioso indígena negado pelo Ocidente como "bruxaria" (KUSCH: 1973, 180). Há tantas culturas quantas possibilidades de ser: em definitivo, a cultura sempre se conjuga no plural.

Kusch dedicou sua vida a tornar patente a potência de sentido propiciada pelas culturas "bárbaras" de América. Com base nisto, pode-se entender sua afirmação enfática - não isenta de perigos - segundo a qual a totalização cultural "é tão correta na cultura aimará, como na quéchua ou na ocidental.” (KUSCH: 1973, 180). Somente uma leitura atenta do conjunto de seu pensamento pode decidir até que ponto essa afirmação acomoda-se a um relativismo multiculturalista ou serve à justificação ética da pluralidade (inter)cultural. Entre o perigo de fetichização das identidades culturais americanas e a tarefa de libertação das culturas americanas colonizadas, o pensamento de Kusch caminha sobre o fio de uma navalha, no coração da ambiguidade.

Caso se queira falar em ética no pensamento de Kusch, será uma ética hermenêutica à la Gadamer -, que estabelece os princípios para a compreensão da cultura do outro, ainda que se trate aqui de um "outro" em sentido mitigado, a um tempo marginal e ancestral, cuja alteridade se encontra radicada na dimensão psíquica mais profunda de si mesmo. ${ }^{10} \mathrm{Em}$ Kusch, o exercício de compreensão consiste na apreensão da essência - ou do "mecanismo central" -

\footnotetext{
${ }^{8}$ Tal como o ilustra Kusch ao afirmar que, na cultura indígena, o objeto é apenas um episódio na totalidade do ritual. (KUSCH: 1973, 181)

${ }^{9}$ Cf., entre outros textos, SCANNONE, J. C., "Sabiduría popular y pensamiento especulativo", p. 57, in Nuevo Punto de Partida de la Filosofía Latino-americana, Buenos Aires: Editorial Guadalupe, 1990.

${ }^{10}$ Para uma discussão sobre ontologia e ética na filosofia latino-americana contemporânea - com destaque para o filósofo-teólogo J. C. Scannone e sua matriz ricoeuriana, cf. DUSSEL, E., Ética de la Liberación en la Edad de la Globalización y la Exclusión, Madrid: Editorial Trotta, 2011, pág. 415 e ss.
} 
do existir do sujeito compreendido; é decifração de seu poder ser à luz do respectivo horizonte cultural. Isto supõe o "sacrifício" de todo cabedal científico prévio, a fim de que aquele que intenta compreender apenas se deixe conduzir e ensinar por quem se oferece à compreensão. Nesse sentido, o assim chamado "trabalho social" com a gente do povo não pode ser conduzido com base no conhecimento científico, pois este (como já referimos) visa explicar objetos conforme a lógica da afirmação, enquanto nos fenômenos sociais se trata de compreender sujeitos - e seus projetos existenciais - a partir de uma lógica da negação. Segundo Kusch, caso se insista em apoiar o trabalho social no conhecimento científico, não é senão pelo interesse político de converter o sujeito observado em coisa passível de dominação.

Semelhante visão crítica da ciência ocidental não poupa sequer o pensamento crítico de Paulo Freire, cujo método de conscientização, para Kusch, estabelece de modo indevido o que deve ser previamente conscientizado, desconsiderando a indeterminação do horizonte cultural daqueles a quem presumimos educar:

Si Freire propone la concientización, es porque ya parte de elementos conscientizados, de los cuales quiere que participe el educando de acuerdo a una lógica de la afirmación. Pero he aqui que si niego estos elementos entro en un campo de indeterminación, según el cual no sé con exactitud qué es lo que debo conscientizar. (KUSCH: 1973, 184)

A fim de abrir caminho à compreensão do povo de América, com seus horizontes culturais indeterminados, Kusch propõe que se substituam as certezas prévias - mesmo as mais críticas - pela "emocionalidade”. (KUSCH: 1973, 182). Com efeito, se é por uma intuição afetiva que o existente se abre à "totalidade de ser", é pela mesma via que é possível iniciar-se em seu mundo, inclusive (no caso americano) em seus elementos "residuais", negados pela ordem civilizada como "primitivos", "inúteis" ou "irracionais". Sem sentir-junto com o homem do povo, não se pode compreender o seu pensamento "seminal", que ordena o mundo a partir de símbolos irredutíveis a conceitos. Sendo assim, para Kusch a emocionalidade não é propriamente "irracional", mas antes "sobrerracional": constitui uma racionalidade "invertida", que opera numa zona de maior indeterminação psíquica e integra o reprimido como "negativo" pelo intelecto, contribuindo para a integração da própria psique ou - o que dá no mesmo - para a desalienação do sujeito.

Seguindo a via da "sobre-racionalidade" emocional, através do campo residualizado pela mentalidade ocidental moderna, chega-se ao núcleo mais profundo do puro existir americano, traduzido por Kusch na categoria de estar, que configura o centro gravitacional da "sabedoria de América" e de seu próprio pensamento, em contraste com a regência do ser no mundo ocidental. 
Por paradoxal que pareça, conforme a linha argumentativa de Kusch, pode-se dizer que, na América, a "totalidade de ser" a que aspira o existente reduz-se, em última instância, ao "mero estar aqui não mais", com toda carga de contingência e provisoriedade ("mero" estar), situacionalidade, pertencimento (estar "aqui”) e gratuidade ("não mais"), evocada ao redor do verbo estar. Estar aqui, na Terra, com a comunidade, para nada: eis um projeto existencial na perspectiva do que hoje se chamaria "ecologia profunda" (deep ecology).

Próprio das culturas agrárias pré-colombianas de América - com seus remanescentes nas periferias das cidades -, o âmbito existencial do estar rege-se pelo vínculo com o ambiente vital e comunitário. Compreende uma dimensão ontológica originária, nutriz, "feminina", que oferece raiz e abrigo ao existente, mas também o reconhece exposto a toda sorte de elementos negativos - caos, doença, morte - que ameaçam sua estabilidade vital. Como se a sabedoria do estar intuísse a dualidade complementar da existência e abraçasse o seu jogo trágico de vida/morte, ordem/caos. À presença ameaçadora do negativo, a sabedoria do estar não responde com enfrentamento e superação, mas com uma "conjuração simbólica", pela qual tenta alcançar o equilíbrio vital entre os opostos. Trata-se de um âmbito existencial estável e estático, que prolonga ao nível comunitário o que Kusch chama a "grande história" da espécie humana, comprometida aqui e agora, em simbiose com todos os seres, em "viver para o fruto" - não mais. ${ }^{11}$

Em contrapartida, o âmbito existencial do ser é próprio da cultura urbana moderna, implementada pela revolução técnica-comercial, que se impõe sobre o ambiente natural a fim de subjuga-lo e possuí-lo. Compreende uma dimensão ontológica ativa, produtiva, "masculina", que responde às ameaças naturais pela edificação da cidade moderna, como fortaleza invulnerável e "pátio de objetos" a serviço da comodidade do homem burguês. Como se o saber moderno também intuísse a dualidade constitutiva da existência, mas ambicionasse expulsar para fora de seus domínios tudo o que é considerado negativo, visando produzir uma ordem sem caos e uma vida sem morte. Trata-se de um âmbito existencial instável e dinâmico, que funda a "pequena história" protagonizada pelo indivíduo moderno atomizado e desenraizado, comprometido em ser alguém a partir da produção de conhecimentos, do acúmulo de bens, da conquista de territórios e do progresso incessante.

Com todo seu aparato técnico e institucional a serviço da ordem, a cidade moderna se caracteriza pelo que Kusch chama de "pulcritude" - um misto de beleza formal e limpeza -,

\footnotetext{
${ }^{11}$ Sobre os conceitos de "estar", “dualidade complementar", “caos/ordem”, "grande história/pequena história” e afins, cf. KUSCH, R., América Profunda, op. cit.
} 
como se mimetizasse o âmbito existencial do "ser" que constitui seu fundamento. Essa cidade "pulcra" aspira ser racional, letrada, legalizada, policiada, higienizada etc.; e, na mesma medida, repele para suas margens a massa pobre, primitiva, iletrada, mestiça, "bárbara", supostamente destituída de qualidade para "ser alguém” dentro de seus domínios. Kusch chama de "fedor de América" a esse aspecto sumamente aversivo, repugnante, atribuído a todas as figuras rejeitadas pela ordem urbana moderna, limitadas a permanecer no mundo ancestral do "mero estar aqui não mais":

Se trata de una aversión irremediable que crea marcadamente la diferencia entre una supuesta pulcritud de parte nuestra y un hedor tácito de todo lo americano. Más aún, diríamos que el hedor entra como categoria en todos nuestros juicios sobre América, de tal modo que siempre vemos a América con um rostro sucio que debe ser lavado para afirmar nuestra convicción y nuestra seguridade. (KUSCH: 2000b, 12-13)

Para Kusch, é justamente desses resíduos "fedorentos" da ordem moderna - e apenas deles - que se pode esperar a proposição de nossa redenção histórica, se é que já não se trata de uma mera questão de mudança no poder político, mas de assumir "América profunda" como eixo de um novo projeto civilizatório: "Diríamos que América está en los temas que son más odiados: pueblo, masa, analfabetismo, índio, negro. En ellos yace la outra parte de nuestro continente, el del mero estar que puede redimirnos." (KUSCH: 2000b, 211)

Em suma, trata-se, em Kusch, da libertação da dominação cultural colonial para a afirmação das raízes populares de América. Tal como ele mesmo o diz:

Cualquier solución en otro sentido, como ser proporcionarles los medios tecnológicos necesarios para su evolución sería prematuro si no se les facilita la evolución de sus propias raíces. De nada vale substituir el arado de madera por el hierro, o imponerles la bomba hidráulica o el uso del jabón, y menos incorporarlos violentamente en la economía del dinero occidental, si no se ha respetado la evolución propia del etnos, su voluntad de ser. (KUSCH: 1973, 186)

\section{Considerações finais}

Supondo já havermos dito o suficiente sobre o limite da visão nacionalista de Diego Pró, à luz da perspectiva dusseliana da Filosofia da Libertação, aproveitamos essas considerações finais para lançar um breve olhar retrospectivo-crítico sobre o pensamento de Rodolfo Kusch, levando em conta alguns de seus aspectos chave.

Aproximar-se do pensamento de Kusch requer uma especial atenção hermenêutica, de tal modo sua inusitada fecundidade conceitual se enlaça a uma ambiguidade portadora de sérios perigos. Poucas vezes, como em Kusch, o povo "bárbaro" e ancestral de América - enquanto sujeito comunitário excluído do sistema colonial - foi compreendido com tanta empatia, rigor e profundidade: quer se trate de desentranhar a subjetividade popular a partir de suas camadas pré-modernas (desafio que segue bastante atual); de tornar patente o sujeito popular como 
alteridade excluída pelo sistema colonial; de mostrar o protagonismo popular como fator de transformação política e social; de caracterizar a seminalidade do pensamento popular, com suas interpelações à tradição filosófica ocidental; ou de aprofundar a dimensão ecológica da cultura popular. Em termos dusselianos: poucas vezes, como em Kusch, se ressalta com tanta veemência a importância decisiva da questão da cultura (neste caso, popular) como conteúdo de vida. ${ }^{12}$ Ou seja, amar, compreender e promover a cultura dos povos de América é um modo fundamental de afirmar a sua vida. Nessa perspectiva, há que reconhecer a valiosa contribuição do pensamento de Kusch ao movimento de libertação dos povos de América contra um sistema colonial que, ademais de explorá-los, os nega em seu modo de ser (estar), viver e pensar.

Por outro lado, deve-se assinalar o perigo de que semelhante interesse por "Nossa América" - em primeira pessoa do plural - venha dar lugar a uma forma mitigada de fetichização da identidade, ou a uma fixação "arqueológica" no pré-colombiano, ou mesmo a uma exaltação nacionalista de viés facistizante. Tanto mais se consideramos o fato de que, em Kusch, muito pouca ênfase é dada à categoria de classe e à questão da exploração econômica. Sem esse corte epistemológico crítico - entenda-se: sem uma apropriação lúcida do marxismo -, é sempre possível que a categoria de "povo" se preste a leituras substancialistas e totalitárias. Convém notar que o próprio autor parece haver resvalado em alguns desses perigos, a julgar por sua controvertida militância peronista na versão mais direitista. Embora, de outro lado, isso não signifique que, necessariamente, as premissas de seu pensamento tenham que resultar numa deriva política dessa ordem. Permanece em aberto, portanto, saber em que medida o ator político Rodolfo Kusch esteve à altura de seu próprio pensamento.

Nesse sentido, a partir de um olhar mais amplo sobre o pensamento de Kusch e consideradas as devidas ressalvas acima, deixamos aqui a questão: até que ponto a "filosofia do enraizamento americano", na linha de Kusch, pode ser apropriada, de modo crítico e fecundo, pela filosofia da libertação em sua versão analética e marxizante?

\footnotetext{
12 Sobre a cultura como conteúdo "material” - ou seja, conteúdo de vida -, cf. DUSSEL, E. 20 Tesis de Política. CDMX: Siglo XXI Editores, 2006, p. 104, 138 e ss.
} 


\section{REFERÊNCIAS BIBLIOGRÁFICAS:}

DUSSEL, E. Oito Ensaios sobre Cultura Latino-americana e Libertação. São Paulo: Paulinas, 1997. .20 Tesis de Política. CDMX: Siglo XXI Editores, 2006.

Ética de la Liberación en la Edad de la Globalización y la Exclusión. Madrid: Editorial Trotta, 2011. 2015. Filosofías del Sur. Descolonización y Transmodernidad. CDMX: Ediciones Akal, Trotta, 2016.

14 Tesis de Ética. Hacia la Esencia del Pensamiento Crítico. Madrid: Editorial Para una Ética de la Liberación Latinoamericana - Tomo II. CDMX: Siglo XXI Editores, 2017.

KUSCH, Rodolfo. "Una lógica de la negación para comprender a América". In VVAA. Hacia una Filosofía de la Liberación Latinoamericana. Buenos Aires: Editorial Bonum, 1973.

$2000 \mathrm{a}$.

La Seducción de la Barbarie. Vol. I das Obras Completas. Córdoba: Editorial Ross,

América Profunda. Vol. II das Obras Completas. Córdoba: 2000b.

PRÓ, Diego F. “Americanismo y europeísmo em Alberdi y Groussac”. In VVAA. Hacia una Filosofía de la Liberación Latinoamericana. Buenos Aires: Editorial Bonum, 1973.

SCANNONE, Juan Carlos. Nuevo Punto de Partida de la Filosofía Latino-americana. Buenos Aires: Editorial Guadalupe, 1990. 